ارزيابى تنوع زنتيكى صفات زراعى و مورفولوزيكى زنوتيڤهاى كنجد

بمهر ام مسعودى' و مهرزاد احمدى

\author{
ا- استاديار موسسه تحقيقات اصلاح و تهيه نهال و بذر، سازمان تحقيقات، آموزش و ترويج كشاورزى، كرج، ايران،

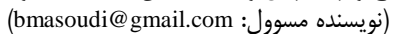 \\ r-كارشناس موسسه تحقيقات اصلاح و تهيه نهال و بذر، سازمان تحقيقات، آموزش و ترويج كشاورزى، كرج، ايران \\ تاريخ دريافت: • •
}

9) صفحه: V V V

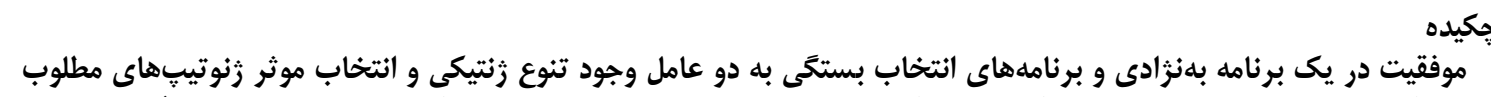

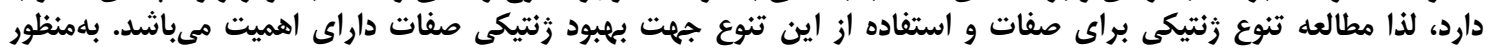

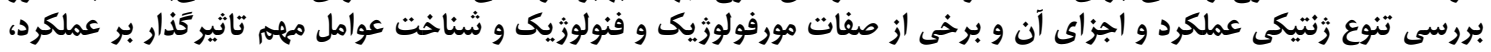

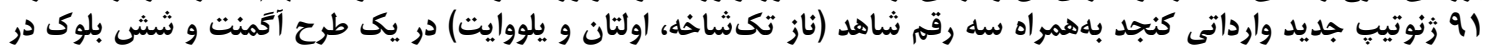

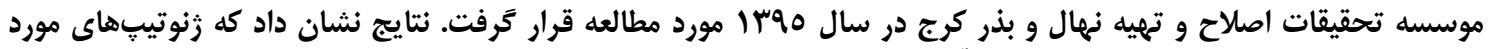

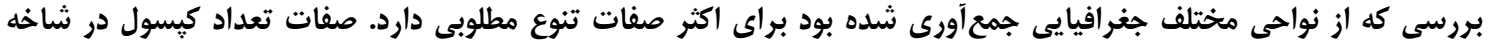

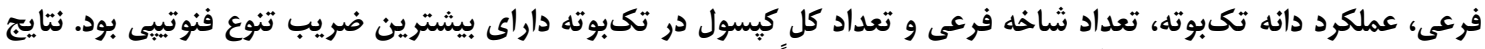

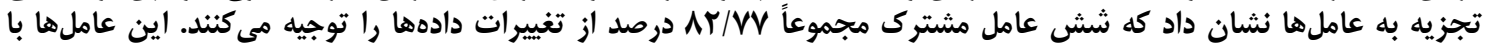

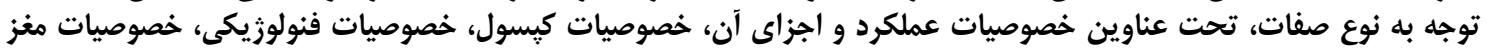

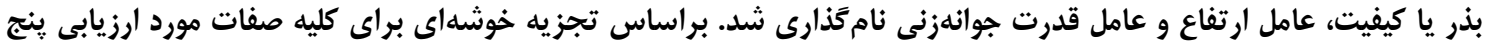

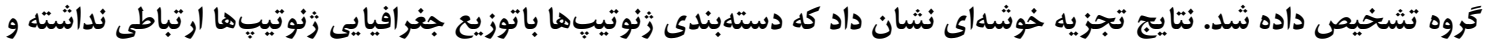

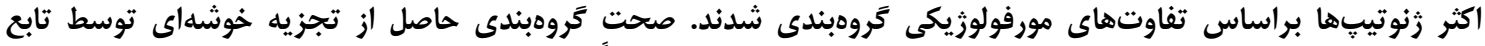

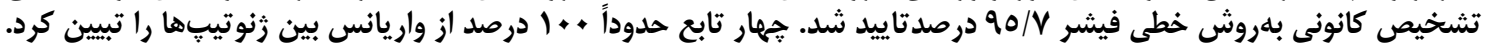

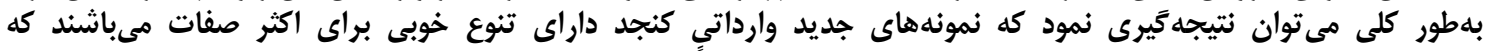

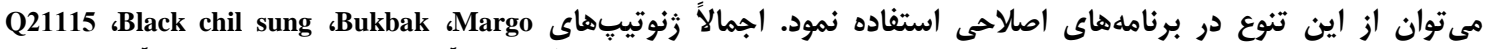

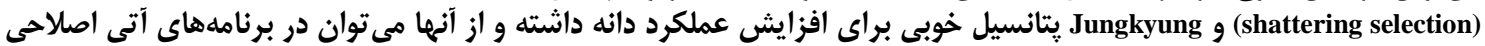

استفاده نمود.

وازههاى كليدى: كنجد، تنوع، تجزيه به عاملها، تجزيه خوشهاى، تجزيه تابع تشخيص

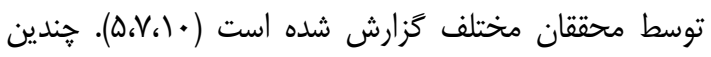

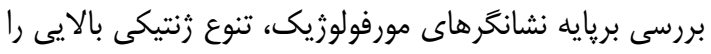

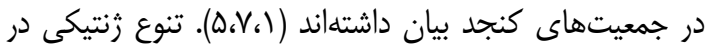
كونههاى گياهى هم توسط كنج

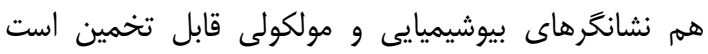

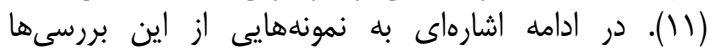

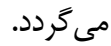

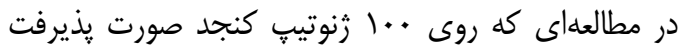

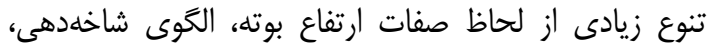

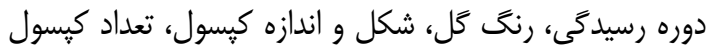

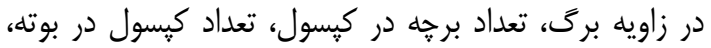

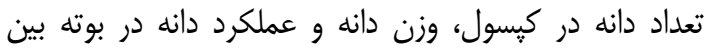

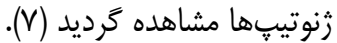

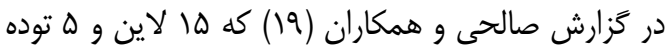

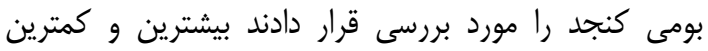

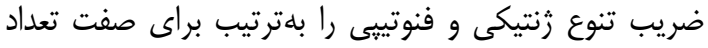

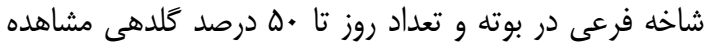

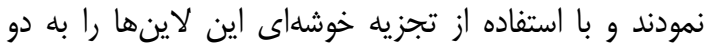
كروه تقسيهبندى نمودند.

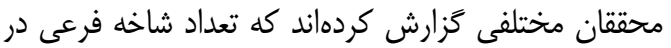

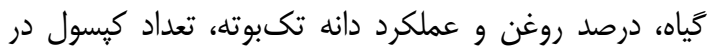

مقدمه

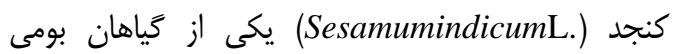

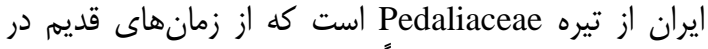

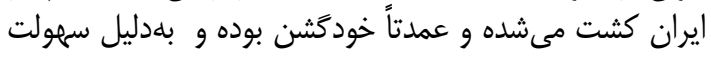

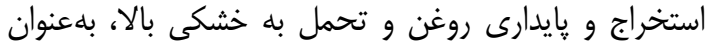

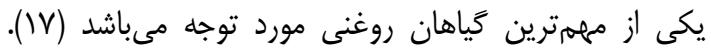

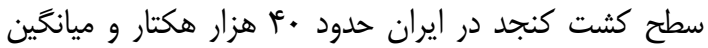

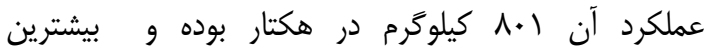

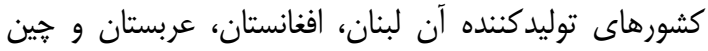
مىباشد (9). استفاده از ارقام اصلاحشده مىتواند موجب افزايش توليد و

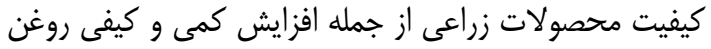

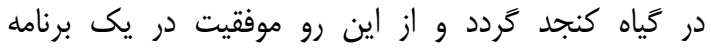

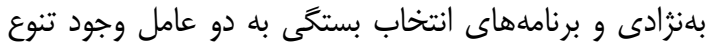

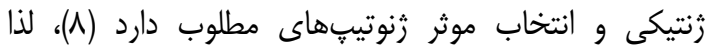

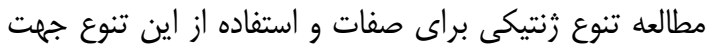

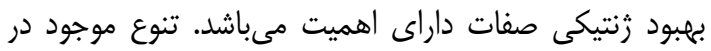

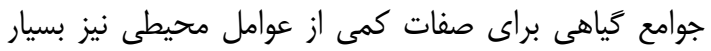

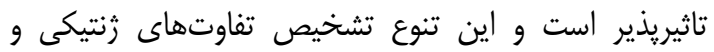

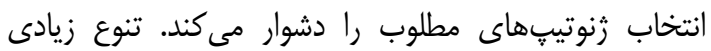

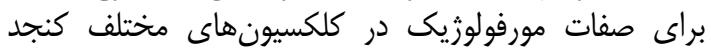


اصلى، در فاكتور جهارم نيز صفت طول ميانكره داراى

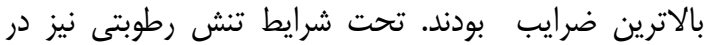

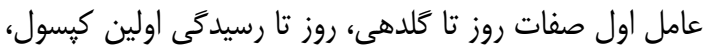

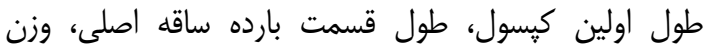

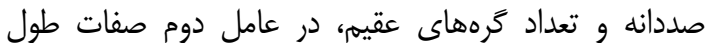

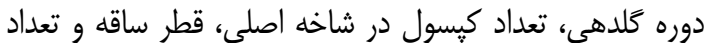

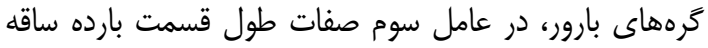

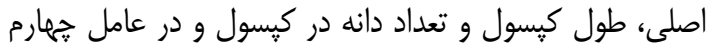

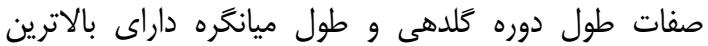

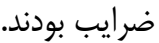

تجزيه خوشهاى روشى است كه مى توتواند براى يبيداكردن

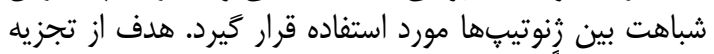

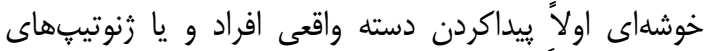

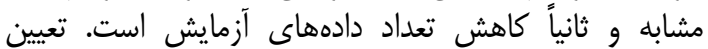

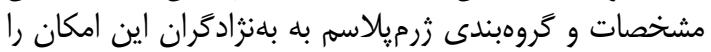

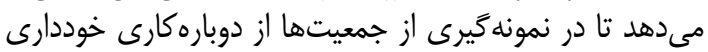

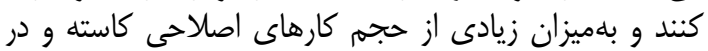

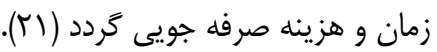

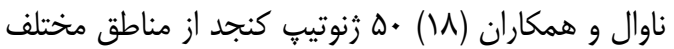

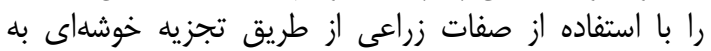

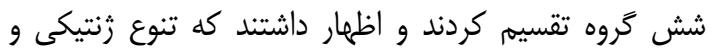

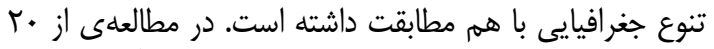

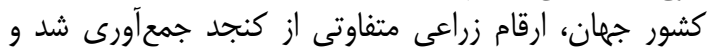

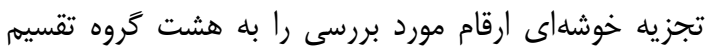

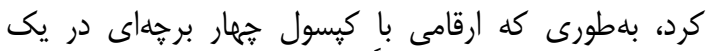

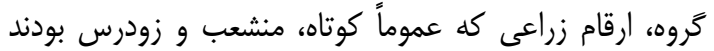

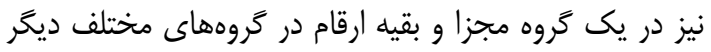

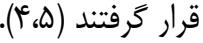

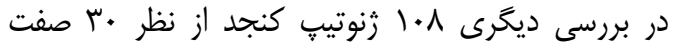

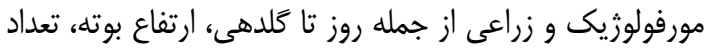

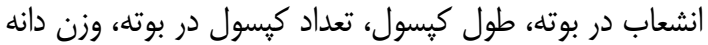

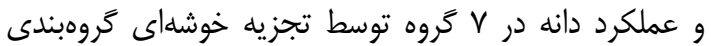

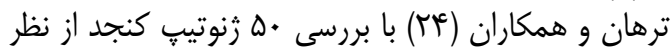

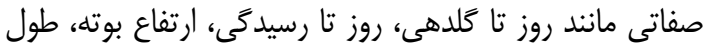

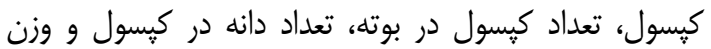

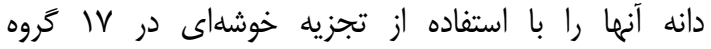

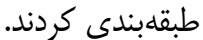
هدف از انجام اين تحقيق بررسى تنوع زنتيكى صفات

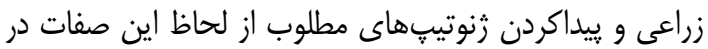

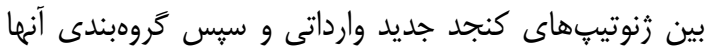

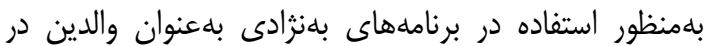

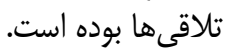

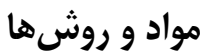

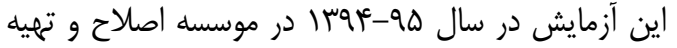

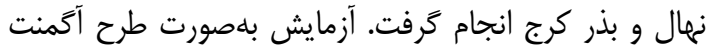

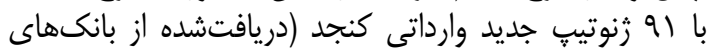
زن كَياهى كشورهاى آلمان، كانادا و استراليا) با سه شاهد (داند (ناز
كياه، ارتفاع گياه و تعداد گره در كَياه داراى بيشترين ميزان

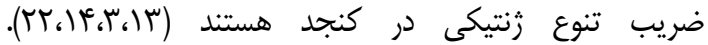

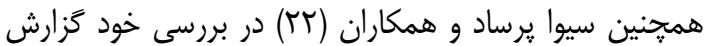

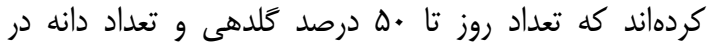
كيسول داراى كمترين ضريب تنوع رُنتيكى بودي

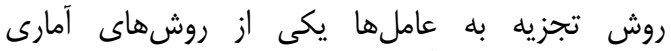

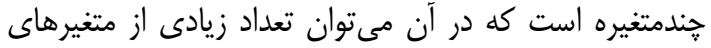

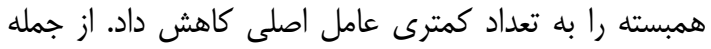

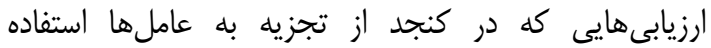

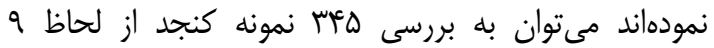

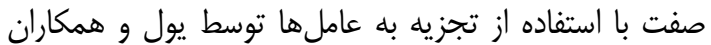

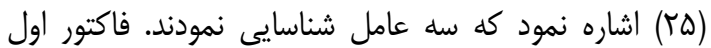

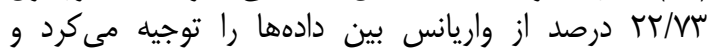

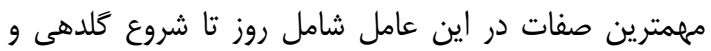

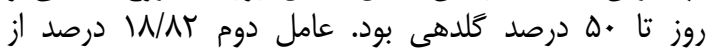

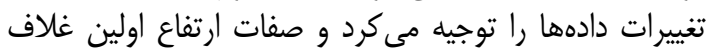

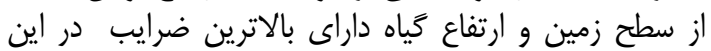

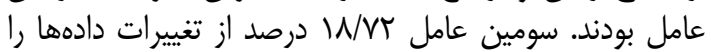

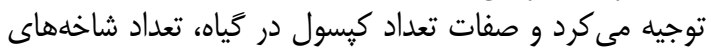

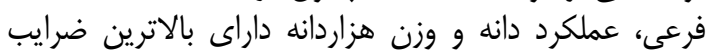

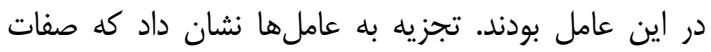

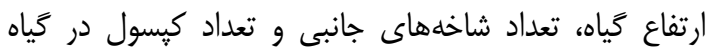
صفات مهمى در عملكرد كنجد هستناه

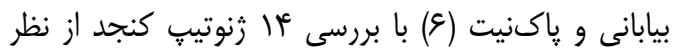

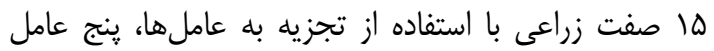

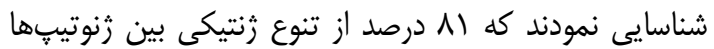

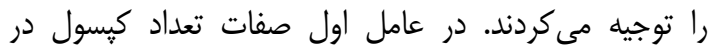

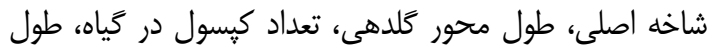
يإيينترين كيسول، قطر ساقه اصلى و ارتفاع كياه با ضرايب

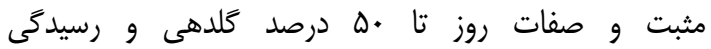

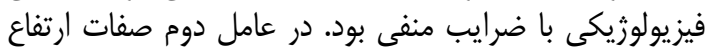

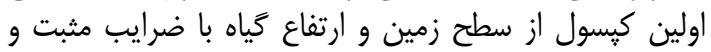

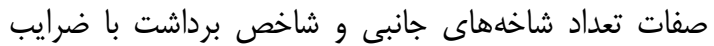

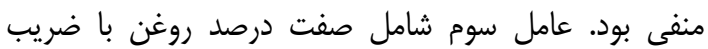

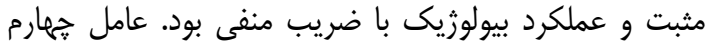

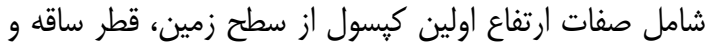

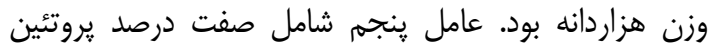

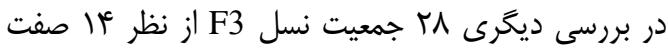

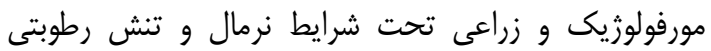

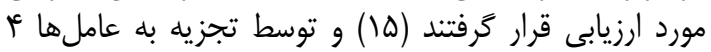

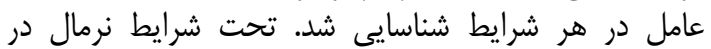

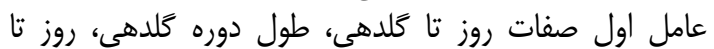

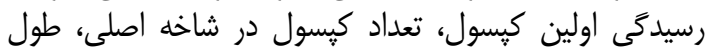

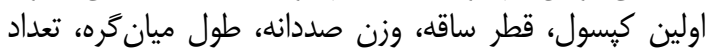

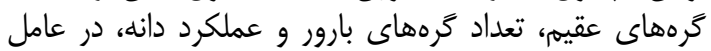

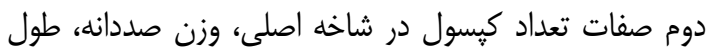

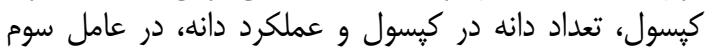
صفات روز تا رسيدن اولين كيسول و طول قسمت بـ بارده ساقه دانه 
محاسبات فوق با استفاده از نرمافزار SPSS نسخه ها انجام

\section{نتايج و بحث}

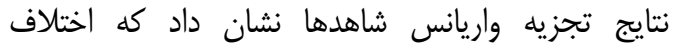

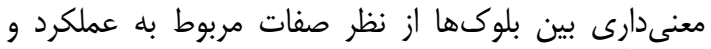

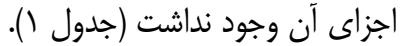

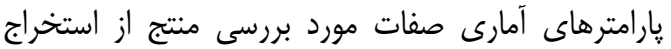

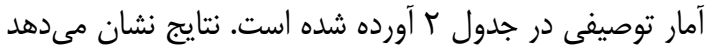

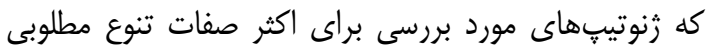

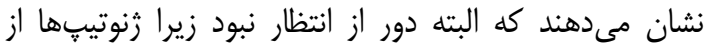

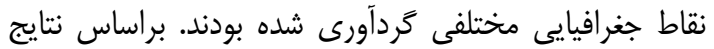

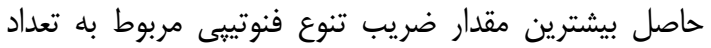

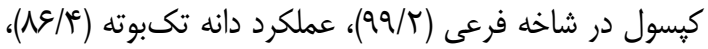

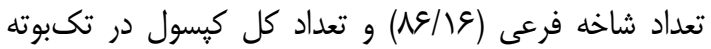
و ومترين ضريب تنوع فنوتيبى مربوط بـ (V)/AD)

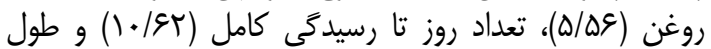

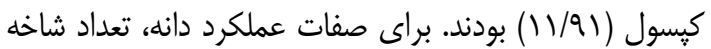

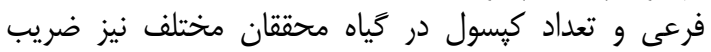

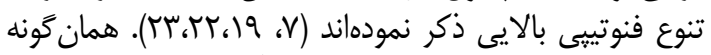

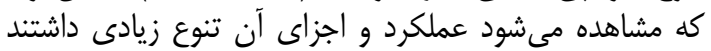

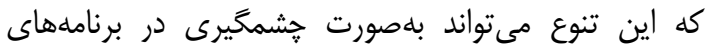

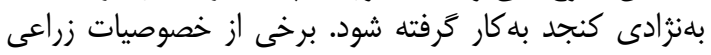

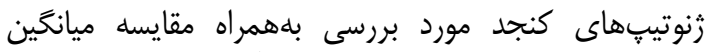

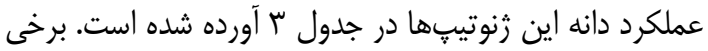

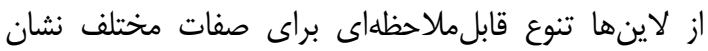

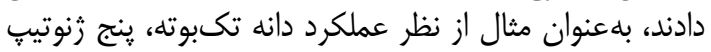
Q21115، Black chil sung ،Bukbak ،Margo و و (shattering selection) دانه، ينج زنوتيب Bukbak ،Japanese golden،

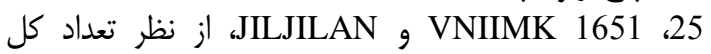

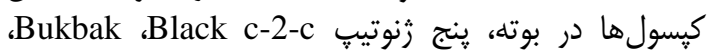
Slack chil sung و و و كيسول ينج زنوتي؟ Beech 173 Q21115 (shattering و Zongzai 7 ،inan 2 داراى ميانگين بالاترى براى صفات ذكر شده

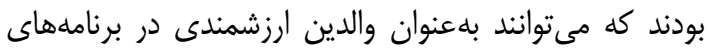
دورگ گيرى براى نيل به آن صفت خاص بن مورد استفاده قرار
تك شاخه، اولتان و يلووايت) و در شش بلوك اجرا شد (جدول

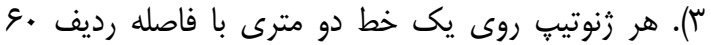

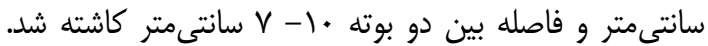

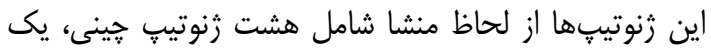

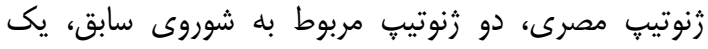

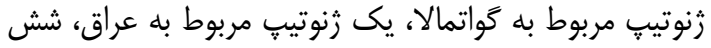

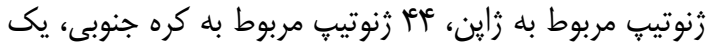

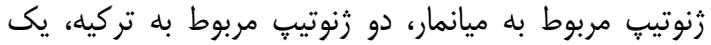

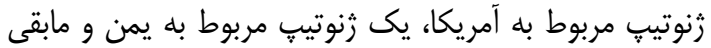

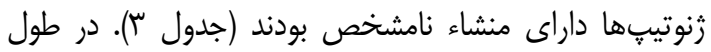
دوره رشد، سه بار وجين دستى انجام شد. اندازهگيرى صنى صفات

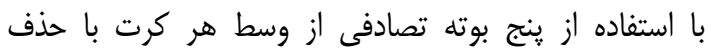

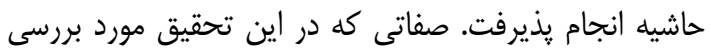

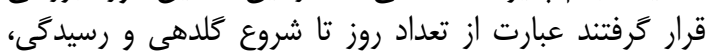

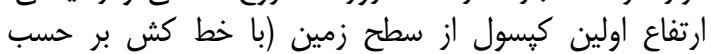
سانتىمتر)، ارتفاع بوته ( با خط كش بر بر حسب سب سانتىمتر)، تعداد

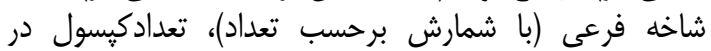

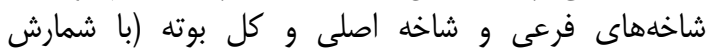

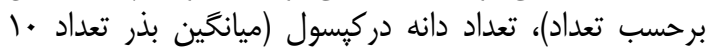

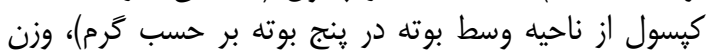

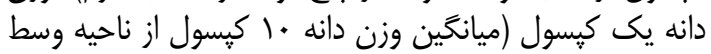

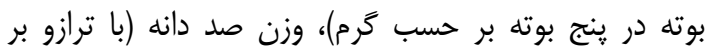

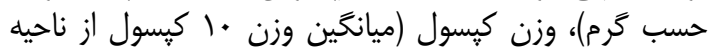

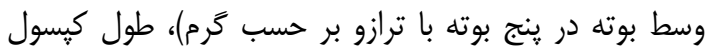

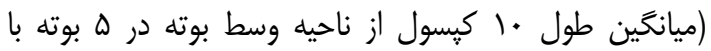

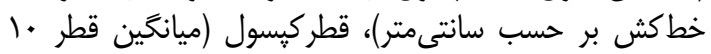

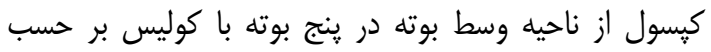

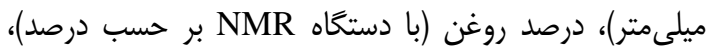

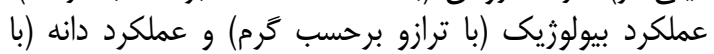
ترازو بر حسب گرم) بودند.

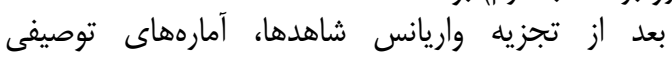

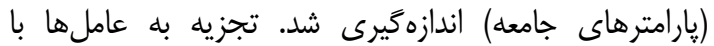

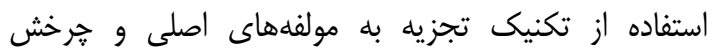

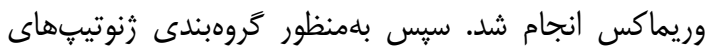

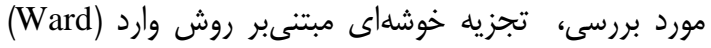

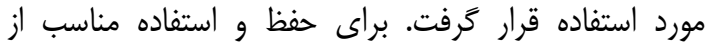

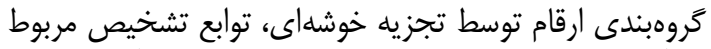

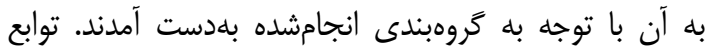
تشخيص بلدست آمده از نوع توابع خطى فيشر بودانه بودند. كليه 
جدول 1- ميانكين مربعات حاصل از تجزيه واريانس شاهدها براى عملكرد دانه و بيولوزيك Table 1. Mean squares obtained from variance analysis of checks for seed and biological yield

\begin{tabular}{|c|c|c|c|}
\hline عملكرد بيولوزيك تك بوته & عملكرد دانه تك بوته & درجه آزادى & منابع تغييرات \\
\hline$\wedge \mathrm{Q} /{ }^{\mathrm{ns}}$ & $r \cdot / \kappa q^{n s}$ & $\Delta$ & بلوى بلو \\
\hline 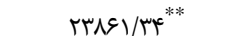 & ง q/rq** & r & زنوتيب \\
\hline Im & $T F / r T$ & 1. & خطا \\
\hline
\end{tabular}

جدول r- مقادير پارامترهاى آمارى صفات مختلف در زنوتيبهاى مورد بررسى Table 2. Values of statistic parameters of different traits in studied genotypes

\begin{tabular}{|c|c|c|c|c|}
\hline درصد ضريب تغييرات & 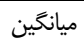 & 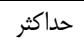 & 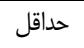 & صفات \\
\hline $1 Q / \mu r$ & $\Delta S / F V$ & Va & r. & تعداد روز تا كلدهى \\
\hline $1 . / 94$ & $11 \% / 9$ & $1 F \Delta$ & $1 \cdots$ & تعداد روز تا رسيدگى كامل \\
\hline 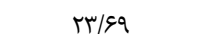 & $Q N / r)$ & ive & 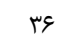 & ارتفاع (سانتىمتر) \\
\hline $5 \% / .9$ & $r r / 1$ & 1.9 & 9 & ارتفاع اولين كيسول از سطح زمين (سانتىمتر) \\
\hline$\Lambda \varepsilon / \backslash$ & r/ATA & re & $\cdot$ & تعداد شاخه فرعى \\
\hline $11 / 91$ & $r q / r r$ & 目 & $\mid V / \Delta$ & طول كيسول (ميلىمتر) \\
\hline $\mid V / q V$ & /DTT & 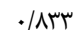 & $\cdot / T$ & عرض كيسول (ميلىمتر) \\
\hline ra/qD &.$/ T \Delta S$ &.$/ 094$ & .110 & وزن يك كيسول (َرم) \\
\hline re/va & 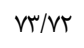 & $1 \cdot V / V$ & Tr/r & تعداد دانه در يك كيسول \\
\hline$r N / V^{C}$ & $\cdot / T \cdot V$ & . ITIV &.$/ \cdot v 9$ & وزن دانه در يك كيسول \\
\hline $99 / \Gamma$ & $\Lambda \Delta / / \gamma$ & fra & · & تعداد كيسول در شاخه فرعى \\
\hline$\Delta Q / 9 q$ & $<q / \Delta q$ & IfD & f & تعداد كֶيسل شاخه اصلى \\
\hline$V \notin / \Lambda \Delta$ & $14 \% / 9$ & sTI & f & تعداد كل كيسولها \\
\hline$t V / N T^{2}$ &.$/ 4 q$ & $.19 V 9$ &.$/ 141$ & وزن صد دانه \\
\hline $91 / .9$ & $\mid \pi / \Lambda$ & Mre. & ra & وزن يك بوته (گرم) \\
\hline$\wedge \varepsilon / 4$ & $19 / .9$ & NT & $\cdot /$ TVE & عملكرد تكبوته (كرم) \\
\hline$\Delta / \Delta S$ & $\Delta \cdot / 1 \infty$ & $\Delta \varepsilon / q)$ & $\mu \kappa / q \Delta$ & درصد روغن \\
\hline
\end{tabular}

جدول ب- خصوصيات زراعى زنوتيڤهاى كنجد مورد بررسى به همراه مقايسه ميانخين براى عملكرد دانه Table 3. Agronomic characteristics of studied sesame genotypes with mean comparison of seed yield

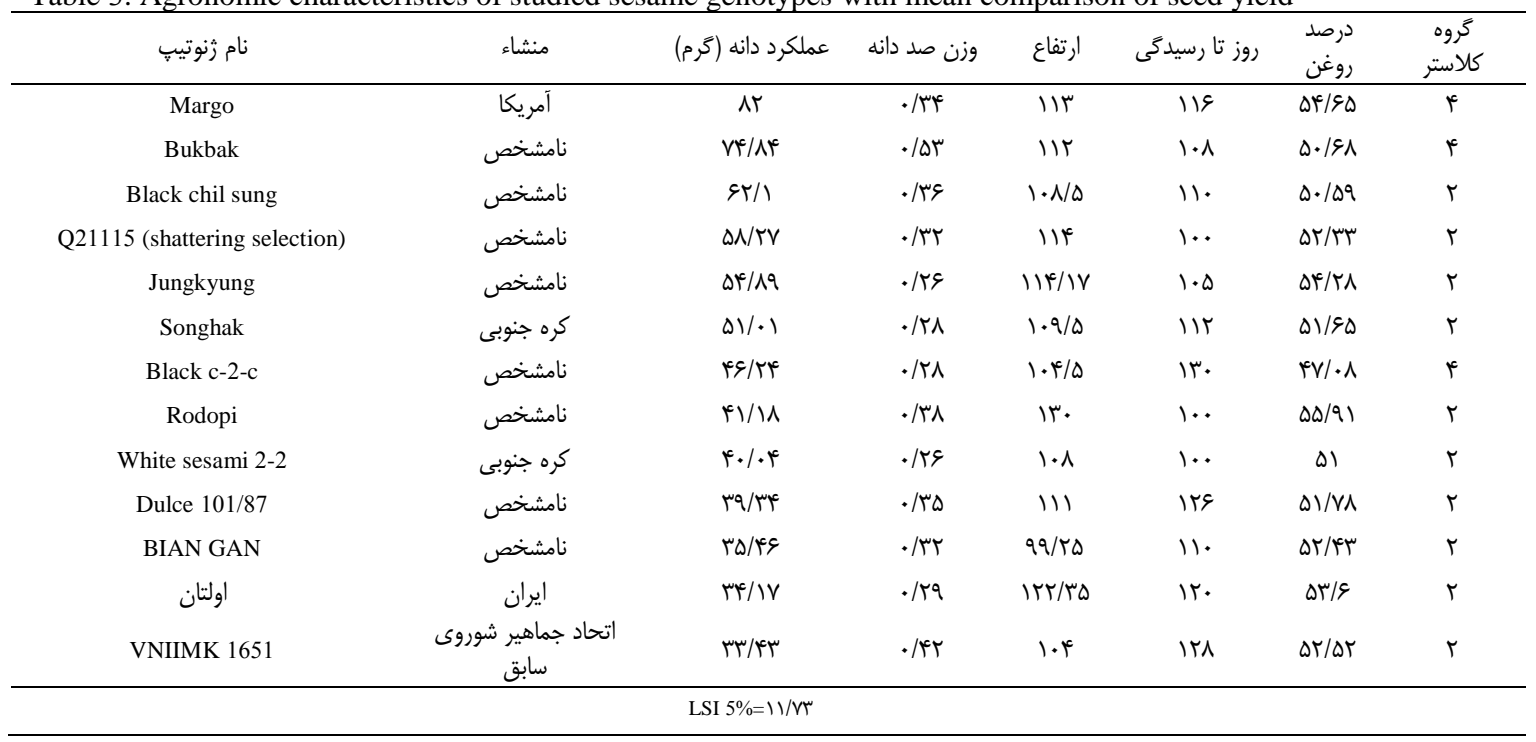


ادامه جدول ب- خصوصيات زراعى زنوتيڤهاى كنجد مورد بررسى به همراه مقايسه ميانخين براى عملكرد دانه Continue of Table 3. Agronomic characteristics of studied sesame genotypes with mean comparison of seed yield

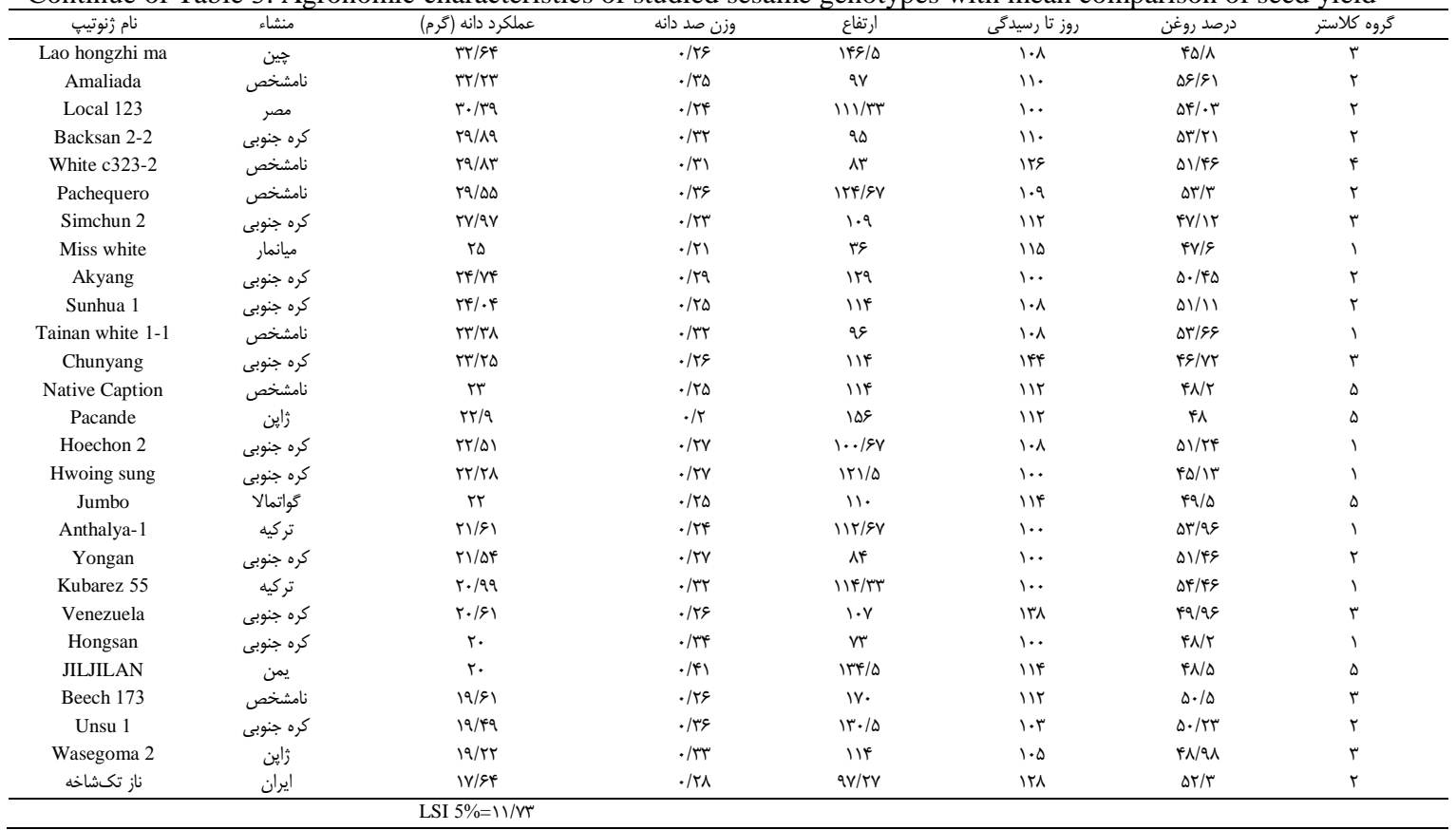

ادامه جدول ب- خصوصيات زراعى ثنوتيڤهاى كنجد مورد بر رسى به همراه مقايسه ميانخين براى عملكرد دانه Continue of Table 3. Agronomic characteristics of studied sesame genotypes with mean comparison of seed yield

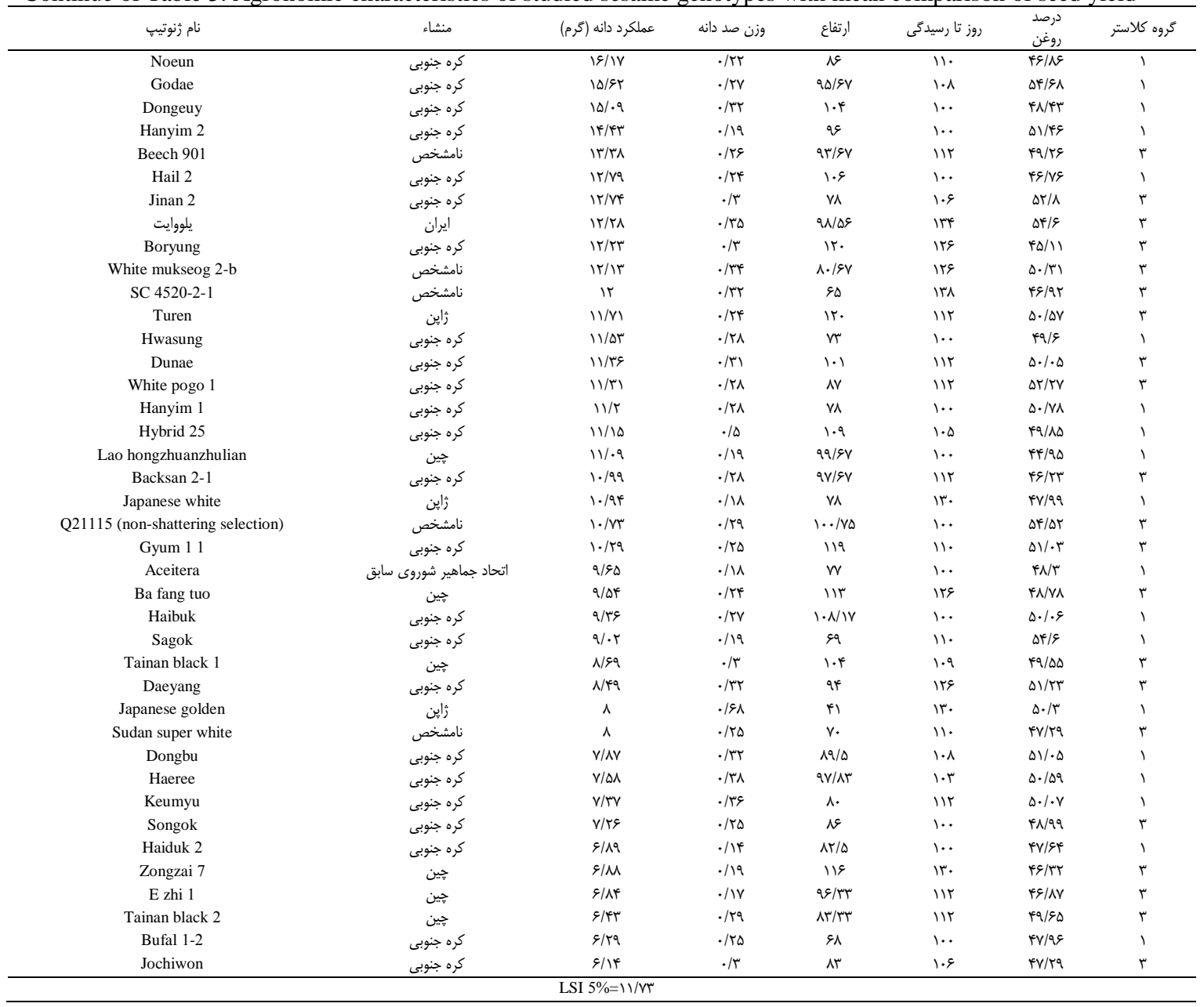


ادامه جدول ب- خصوصيات زراعى ثنوتيبهاى كنجد مورد بررسى به همراه مقايسه ميانخين براى عملكرد دانه Continueof Table 3. Agronomic characteristics of studied sesame genotypes with mean comparison of seed yield

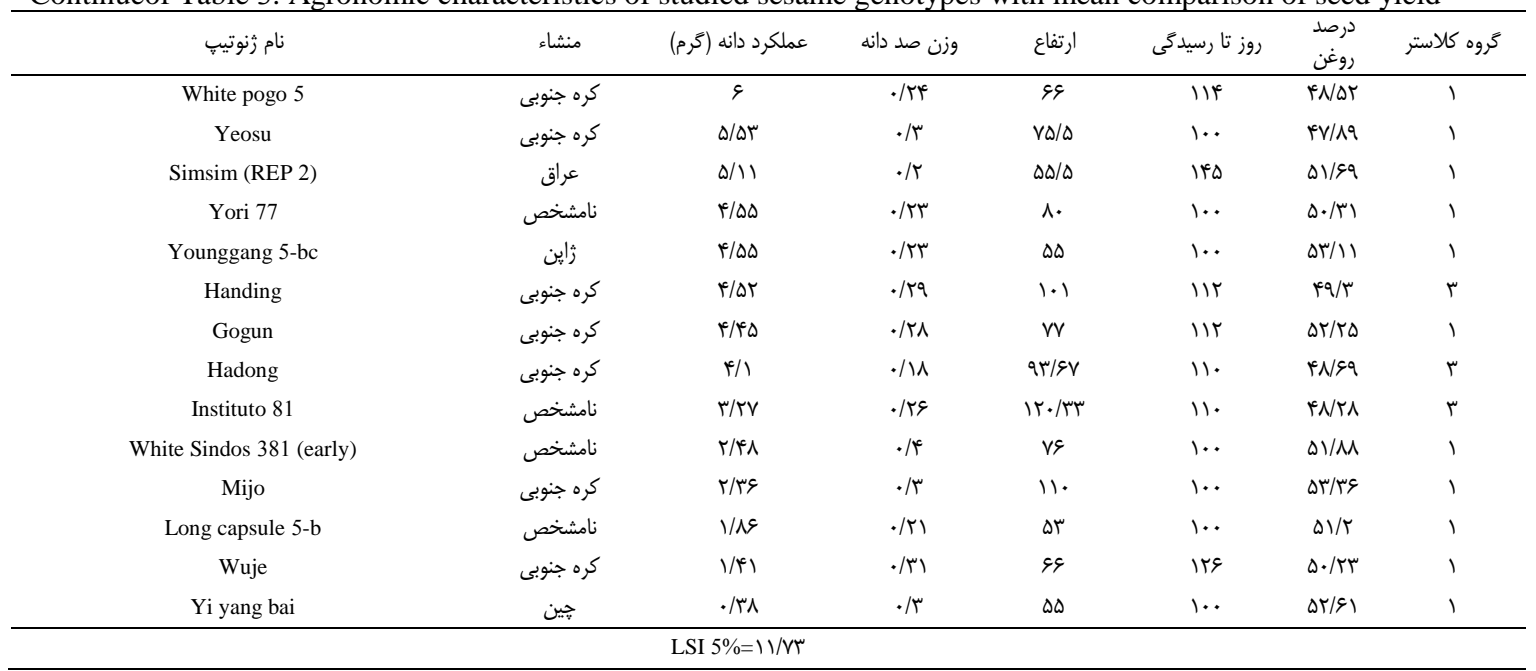

صفات مرتبط با كيسول داشت، اين عامل تحت نام نام

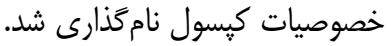

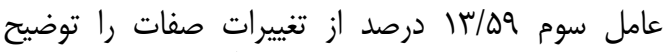

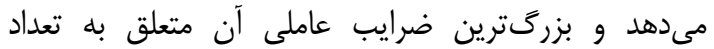

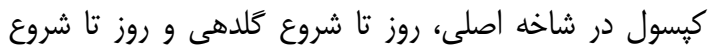

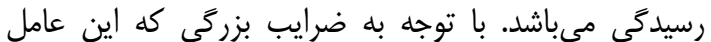

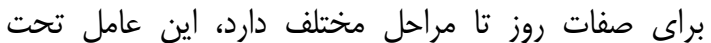

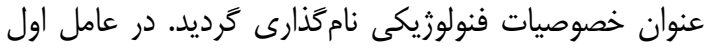

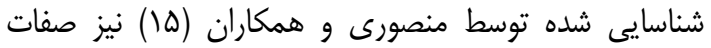

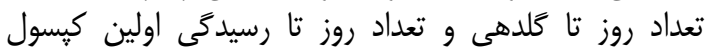

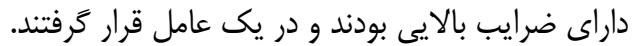

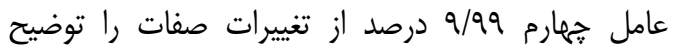
مىدهد و بزرگترين ضرايب عاملى آن متعلق به قطر كيسول

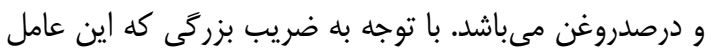

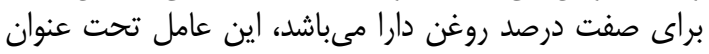

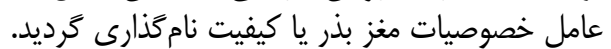

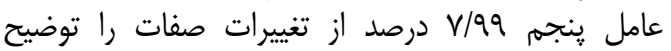

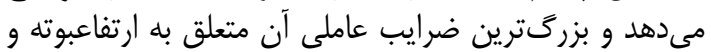

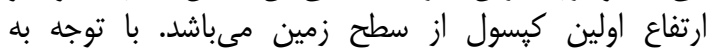

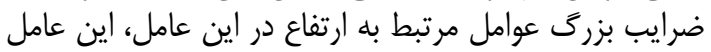

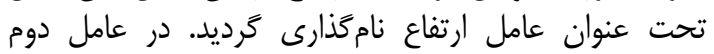

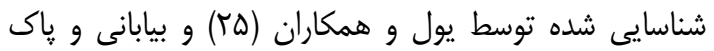

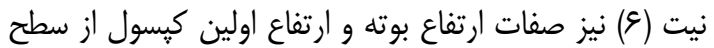

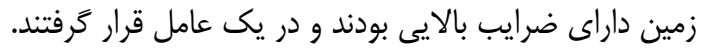

تجزيه بله عاملها

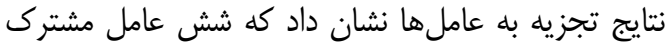

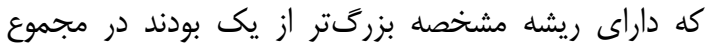

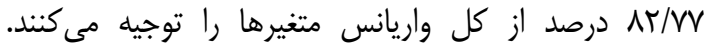

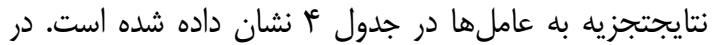

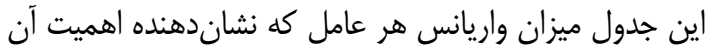

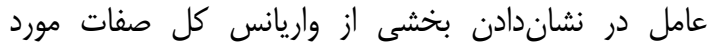

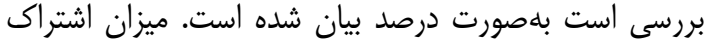

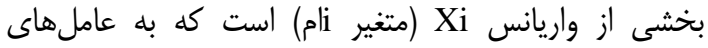

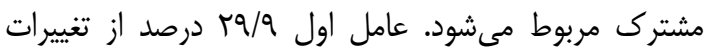

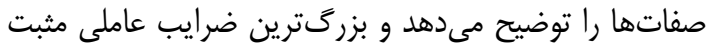

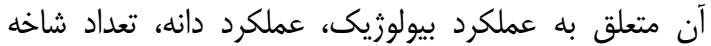

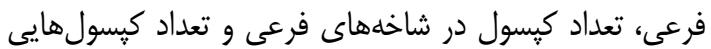

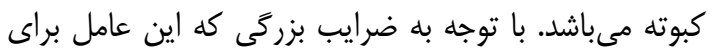

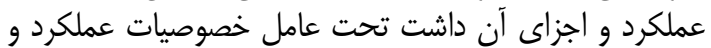

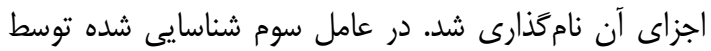

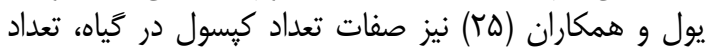

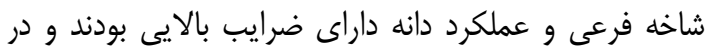

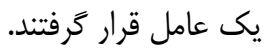
عامل دوم ها درصد از تغييرات صفات راتئد رات توضيح مى دهد

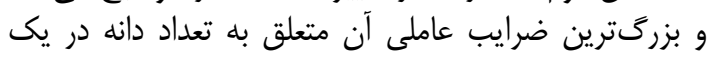

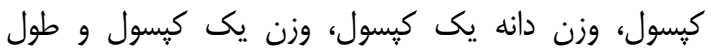
كيسول مىباشد. با توجه به ضرايب بز ئركى كه اين عامل براى 
Table 4. Factor analysis results for all measured traits

جدول ع- نتايج تجزيه به عاملها براى كليه صفات مورد اندازهگيرى

\begin{tabular}{|c|c|c|c|c|c|c|}
\hline صفات & عامل اول & عامل دوم & عامل سوم & عامل جهارم & عامل ينجم & عامل ششم \\
\hline عملكرد بيولوزيك & $.199^{*}$ &.$/ 1 f$ &.$/ T F$ & - ( &.$/ \cdot r$ & $-\cdot / \cdot f$ \\
\hline عملكرد دانه & $\cdot 19^{*}$ & .119 & $-\oplus / T V$ & -.1 .9 & $\cdot 1 \cdot 1$ & $\cdot 1 \cdot \mathrm{f}^{\mathrm{f}}$ \\
\hline تعداد دانه در يى كֶسول &.$/$ & $\cdot / \mathcal{N}^{*}$ &.$- / \cdot r$ & $\cdot 1 \cdot \Delta$ & r & - \\
\hline وزن دانه يك كِسول & $-\cdot / \cdot 1$ & $\cdot / \mathrm{M}^{*}$ & $-\cdot 1 \cdot t^{\mathrm{f}}$ & $.1 \cdot 1$ & $-\cdot / 1$ & $\cdot / 4 \Lambda$ \\
\hline وزن صد دانه & س. & .1 .9 & -.1 .9 & .1 & $-\cdot / \mathrm{IV}$ & $\cdot / 99^{*}$ \\
\hline وزن يك كيسول & $\cdot|\pi|$ & $\cdot / \Lambda \Delta^{*}$ & $\cdot / \cdot \Delta$ & ع &.$/ 1$ &.$/ 1 f^{f}$ \\
\hline طول كֶيسول & $\cdot / T \Delta$ &.$|9|^{*}$ & - &.$- / 19$ &.$/ 19$ & $.1 \cdot 1$ \\
\hline قطر كيسول & $\cdot / \Lambda$ &.$/ 10 \Delta$ & عس/•- & $\cdot 109^{*}$ &.$/ 11$ &.$/ \cdot t$ \\
\hline ارتفاع بوته & 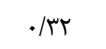 & $\cdot / 4 q$ & $-\cdot / 4 q$ & . & $\cdot / \Delta r^{*}$ & $-\cdot 1 \cdot v$ \\
\hline ارتفاع اولين كِيسول از سطح زمين &.$/ 11$ & .1 .9 & $-\cdot 1 \cdot 0$ &.$/ 10$ & $\cdot / 1 \varepsilon^{*}$ &.$- / 11$ \\
\hline تعداد شاخه فرعى & $\cdot / V r^{*}$ & .1 & זس/. & $-\cdot / 4 \Lambda$ & - & $\cdot 1 \cdot \Delta$ \\
\hline تعداد كِيسول در شاخههاى فرعى &.$/ 9 r^{*}$ & .1 .9 &.$/ .4$ & $.1 \cdot 1$ &.$/ 1$ &.$- / \cdot r$ \\
\hline تعداد كيسول در شاخه اصلى & $\cdot / T^{\mathrm{E}}$ &.$/ 4$ &.$- / \Delta \Delta^{*}$ & . & $-\cdot / \mu \wedge$ & - \\
\hline تعداد كيسولهاى يك بوته &.$/ 90^{*}$ & $.1 \cdot 1$ &.$- / 10$ &.$/ 11$ & -.1 .9 & $-\cdot / \cdot 0$ \\
\hline درصد روغن & .1 .9 & $\cdot 1 \cdot \Delta$ &.$- / 4 V$ & $-\cdot / \Lambda e^{*}$ & 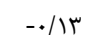 & $.1 \cdot 1$ \\
\hline روز تا شروع گلدهى & $-\cdot / \cdot 4$ & $\cdot 1 \cdot \mathrm{r}^{\mathrm{c}}$ & $. / 9)^{*}$ &.$/ 11$ & .1 &.$- / 14$ \\
\hline روز تا شروع رسيدگى & $\cdot / K F$ & $\cdot / K F$ & $\cdot \mid 9 \Lambda^{*}$ & .119 & $-\cdot / \mu$ & $.1 \cdot 1$ \\
\hline مقدار ويثه & $\Delta / \cdot \Lambda$ & $r / \Delta V$ & T/M & $1 / v$ & (1/R & $1 / \cdot 0$ \\
\hline درصد واريانس & $r q / 9$. & $10 / 1$. & $15 / 09$ & $9 / 99$ & V/৭9 & $s / r$. \\
\hline درصد تجمعى واريانس & rq/q. & $F \Delta / \cdot$ & $\Delta N / \Delta Q$ & SN/DN & $V \& / \Delta V$ & $\Lambda r / V V$ \\
\hline
\end{tabular}

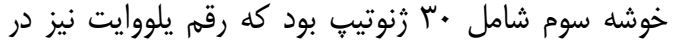

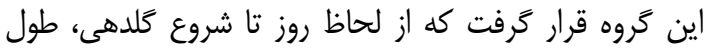

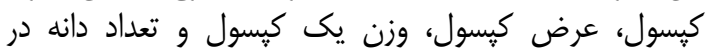

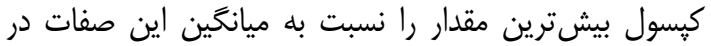

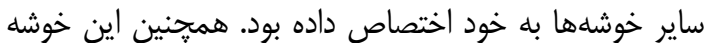

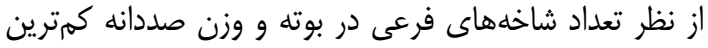
مقدار را نسبت به ميانگين اين صفات فرعات در ساير خوشهها بها به خود

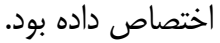

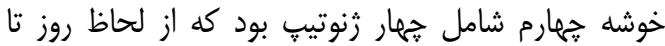

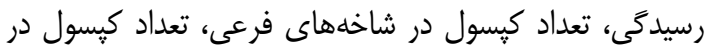

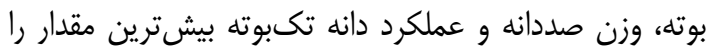

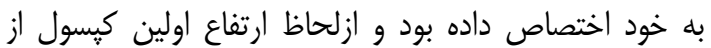

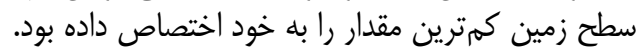

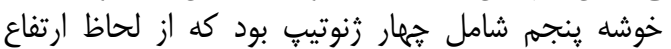

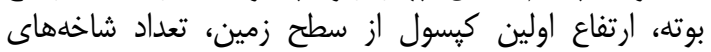

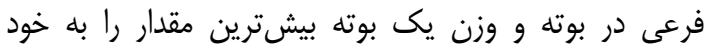

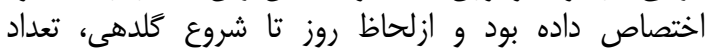

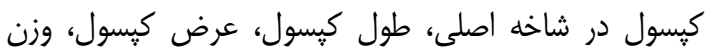

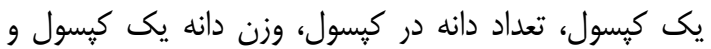

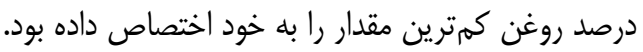

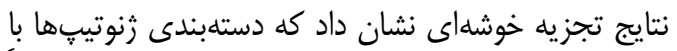

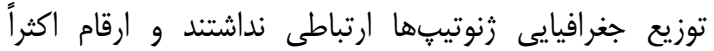

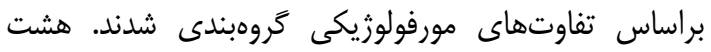

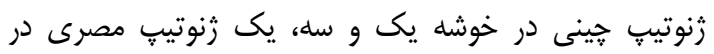

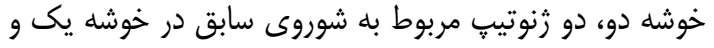

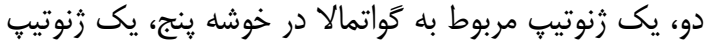

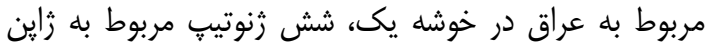

عامل ششم ب/ و درصد از تغييرات صفات را توضيح

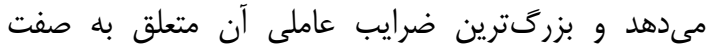

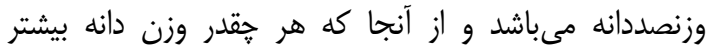

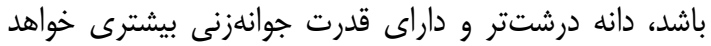

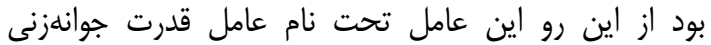
نام تذارى شد.

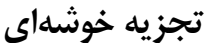

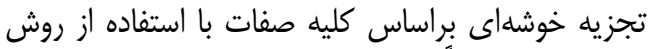

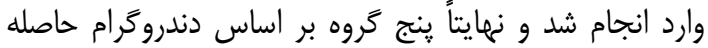

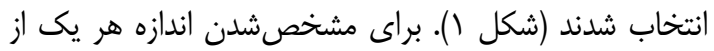

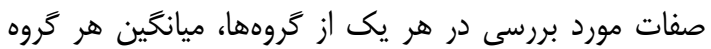

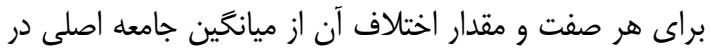

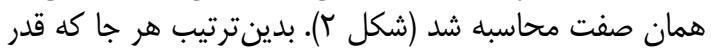

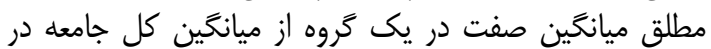

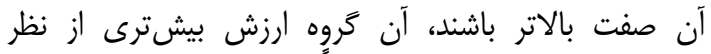

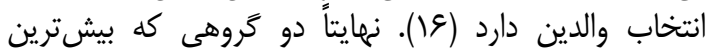

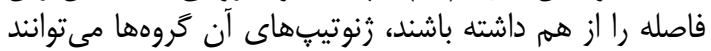

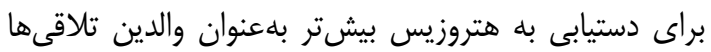

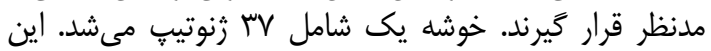

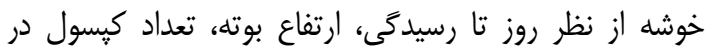

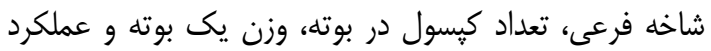

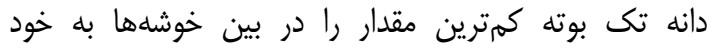

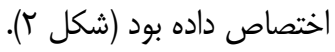

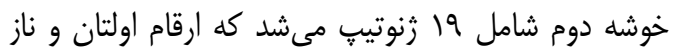

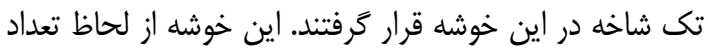

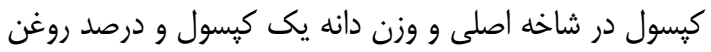

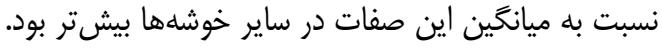


صفات در هر تابع مىتوان به اهميت نسبى هر صفت در تمايز

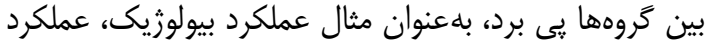

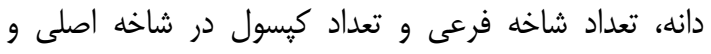

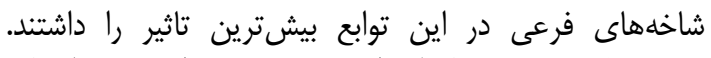

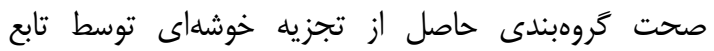

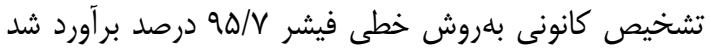

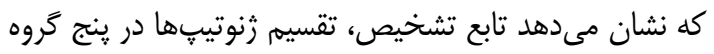

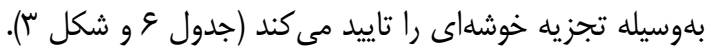

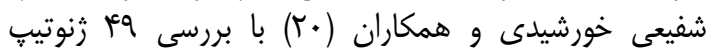

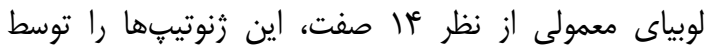

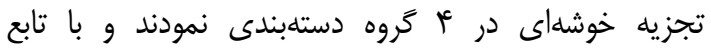

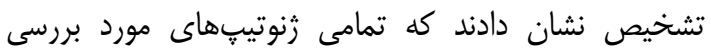

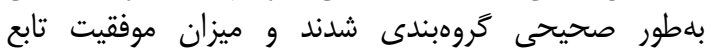

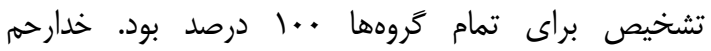

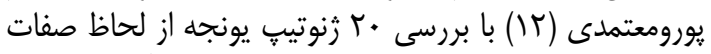

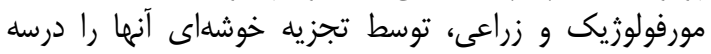

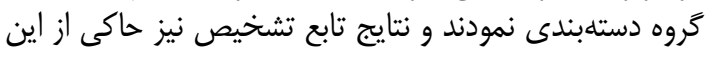

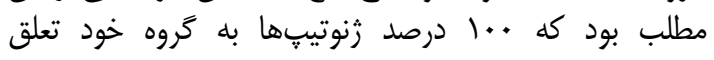
داشتند.
در خوشهاى يك، سه و ونج، أبا زنوتيب مربوط به كره

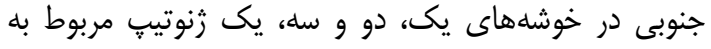

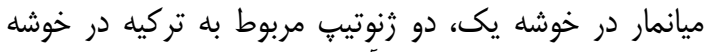

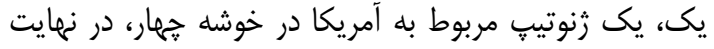

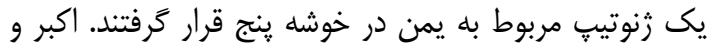

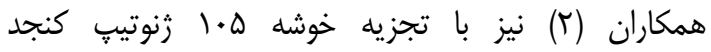

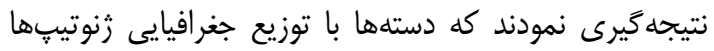

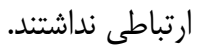
تجزيه تابع تشخيص ناشني

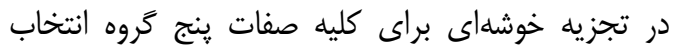

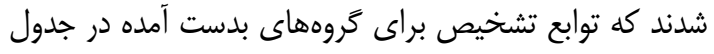

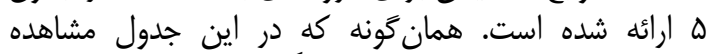

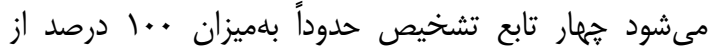

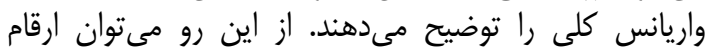

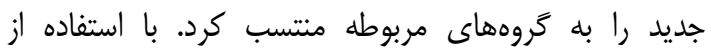

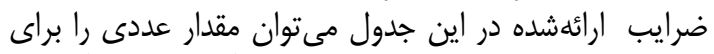

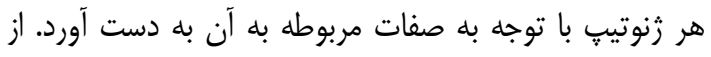

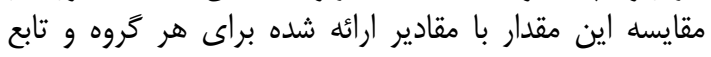

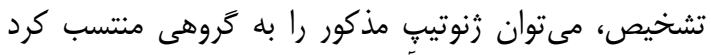

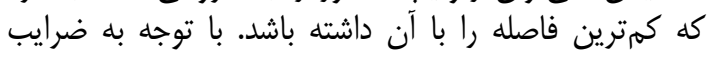




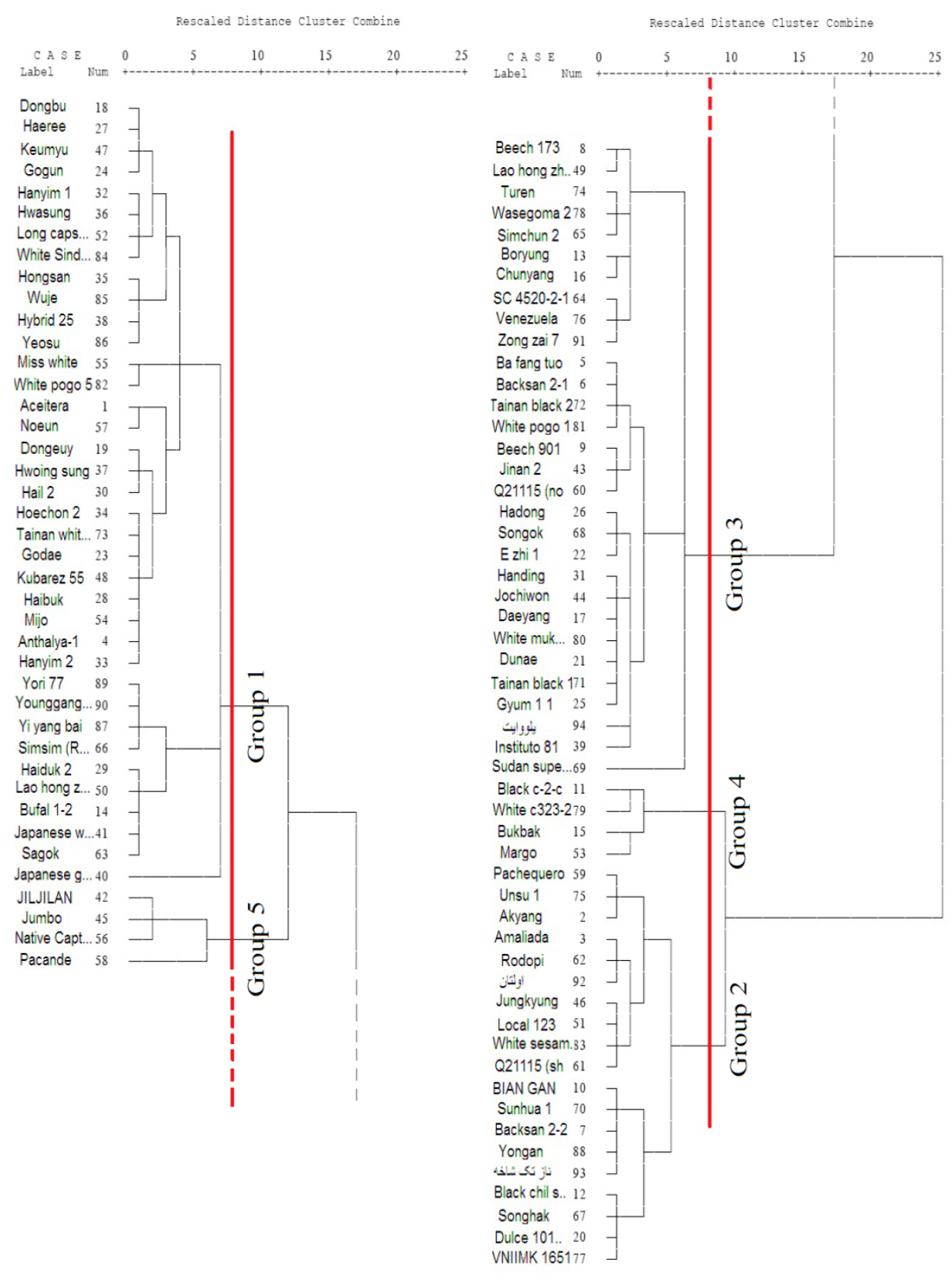

شكل 1- دندروگرام حاصل از تجزيه خوشهاى عq زنوتيب كنجد

Figure 1. The dendrogram of cluster analysis of 94 sesame genotypes 


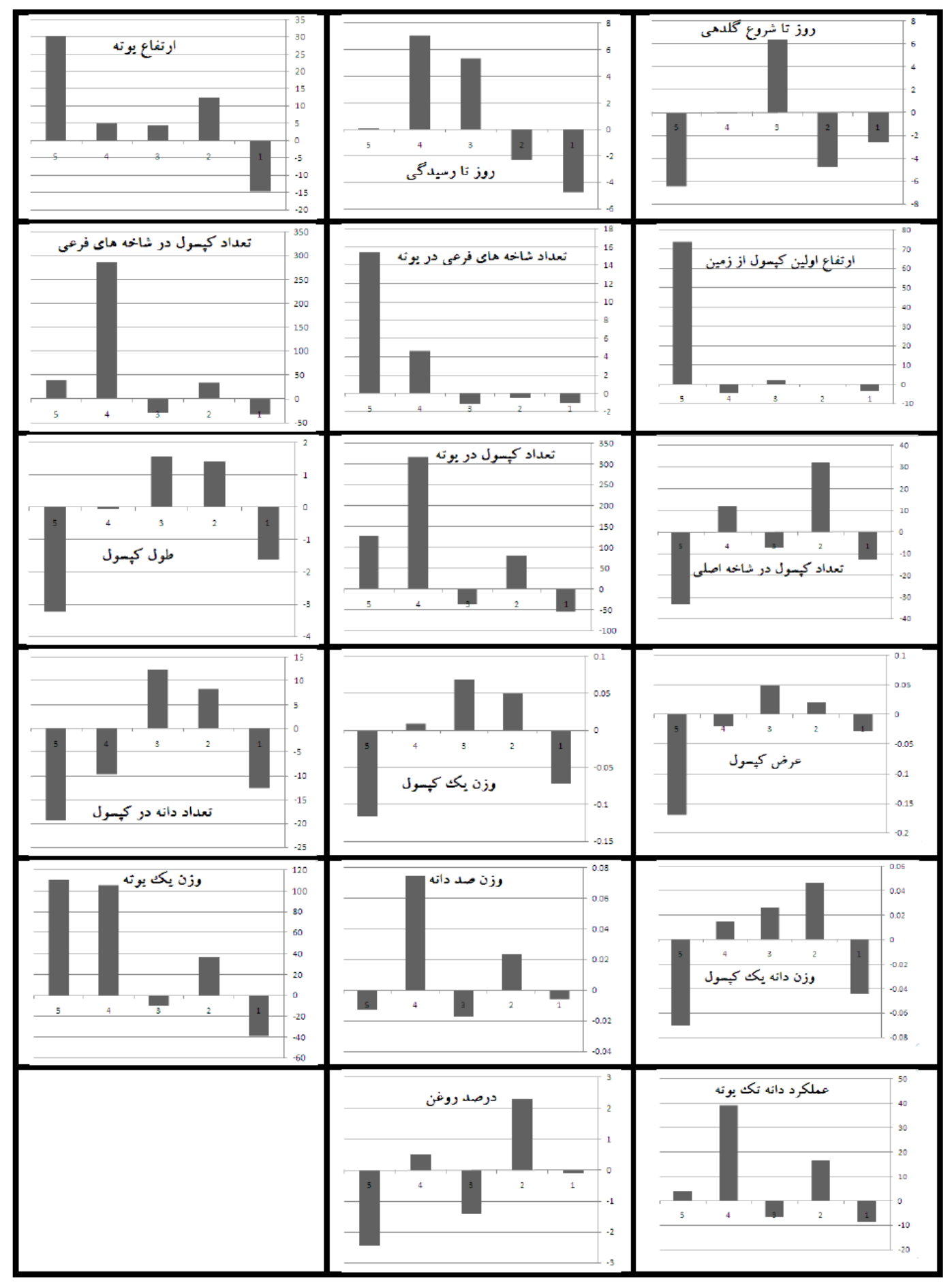

شكل r- انحر اف استاندارد هر خوشه از ميانخين كل براى صفات مختلف

Figure 2. Standardized deviation of each group's mean from total mean 
جدول ه- ضرايب استاندارد شده صفات در توابع تشخيص به همر اه مقادير ويزه و درصد تبيين واريانس Table 5. Standardized discriminate function coefficients of traits along with eigen value and percentage of variance determination

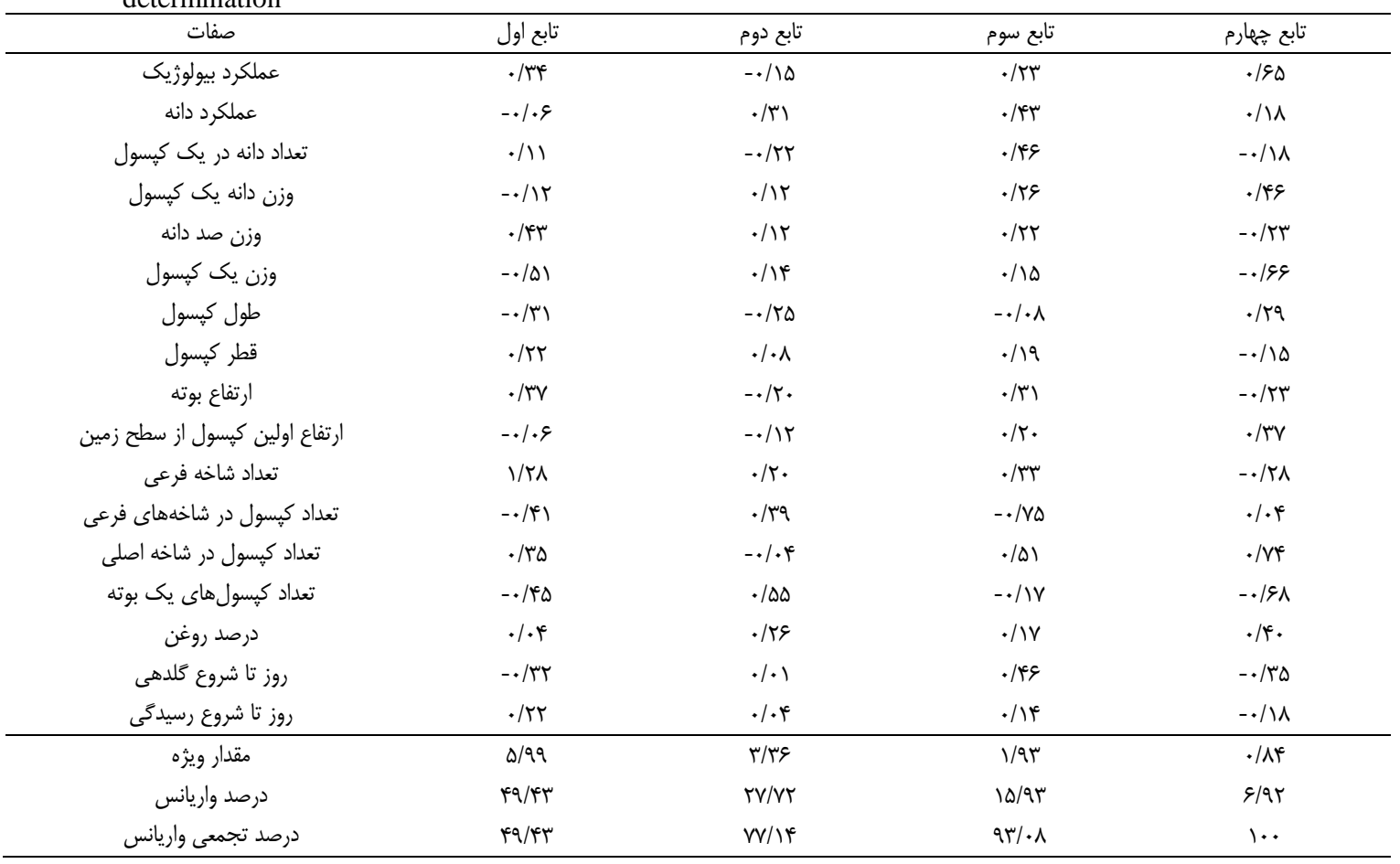

جدول צ- نتايج تابع تشخيص براى صحت گروهبندى زنوتيبهاى كنجد Table 6. Discriminate function results for the accuracy of grouping of sesame genotypes

\begin{tabular}{|c|c|c|c|c|c|c|c|c|}
\hline & \multirow{2}{*}{ كروهبندى } & & \multicolumn{5}{|c|}{ اعضاى گروه } & \multirow{2}{*}{ جمع كل } \\
\hline & & & 1 & $r$ & r & f & $\Delta$ & \\
\hline \multirow{7}{*}{ اصلى } & \multirow{4}{*}{ مجموع } & 1 & عس & 1 & . & • & - & rv \\
\hline & & $r$ & . & $M$ & 1 & . & . & 19 \\
\hline & & r & 1 & 1 & rA & • & . & r. \\
\hline & & $\Delta$ & . & . & . & . & p & r \\
\hline & \multirow[b]{3}{*}{ درصد } & 1 & qV/T. & $r / V$. & . & . & . & $1 \ldots$ \\
\hline & & $r$ & • & $q 4 / v{ }^{c}$ & D/TG & • & • & $1 \ldots$ \\
\hline & & r & سא/ץ & سא/ץ & سז/س9 & • & • & $1 \ldots$ \\
\hline
\end{tabular}




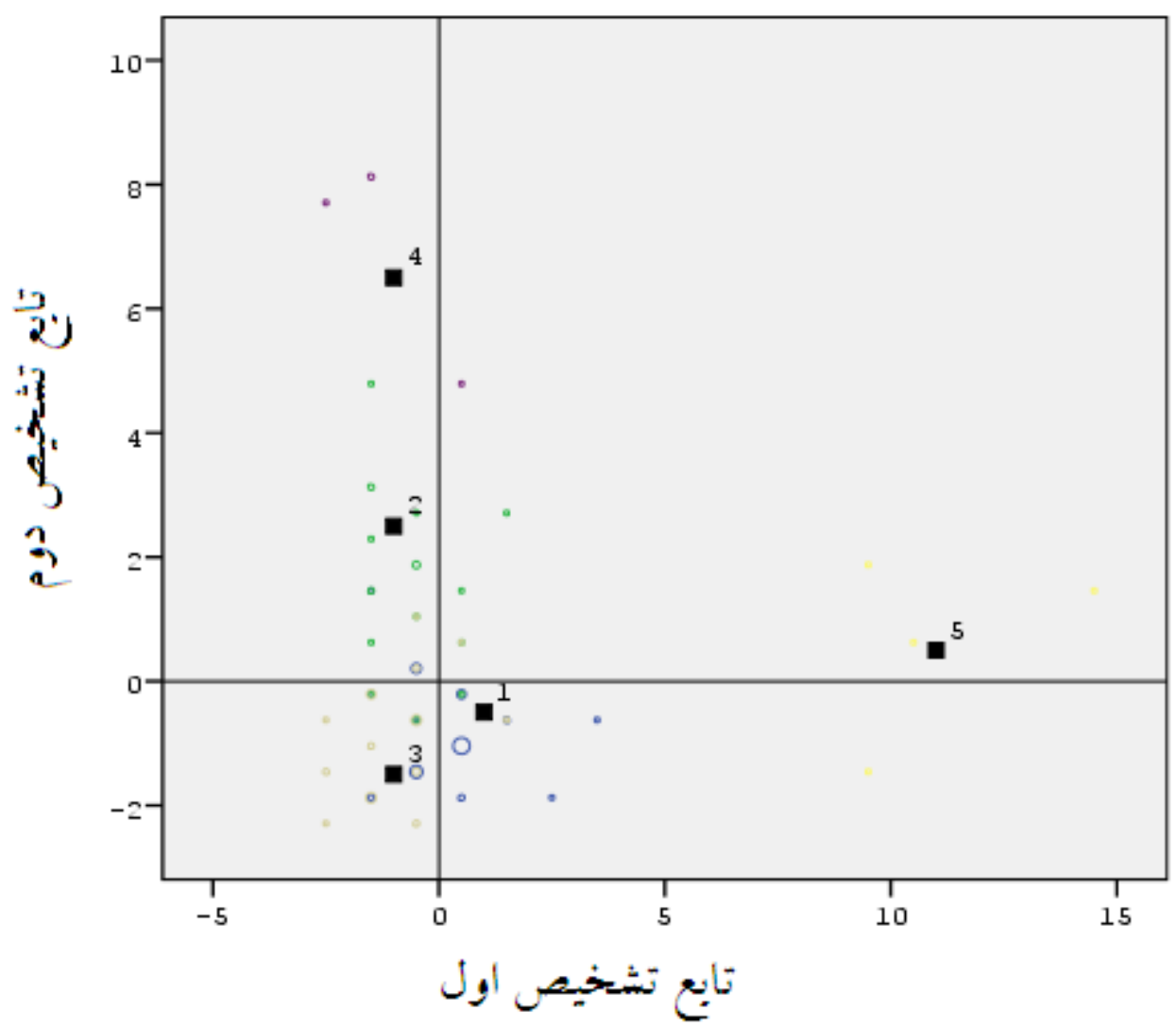

شكل س- گ رووبندى زنوتيبهاى مختلف بر اساس تابع تشخيص

Figure 3. Grouping different genotypes based on discriminate function

كه بايستى از تكنيك تلاقى استفاده شود يا اگر محقق

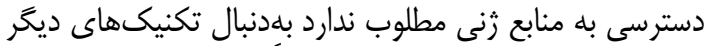

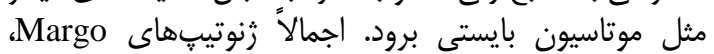
Q21115 (shattering ،Black chil sung ،Bukbak

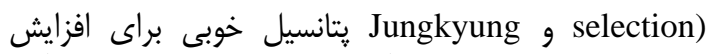

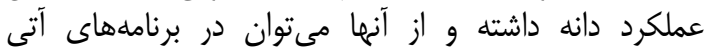
اصلاحى استفاده نمود.

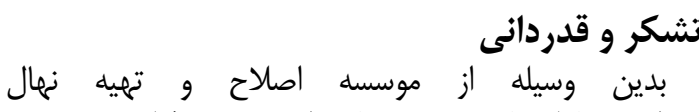

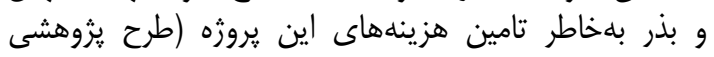

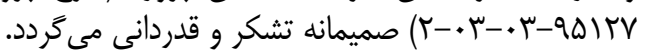

بلهور كلى در بين زنوتيڤهاى مورد بررسى از نظر اكثر

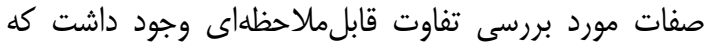

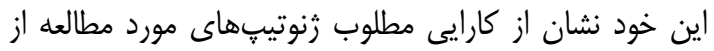

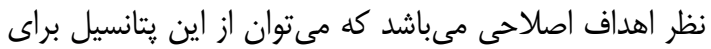

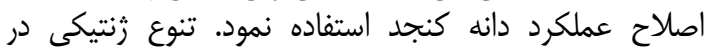

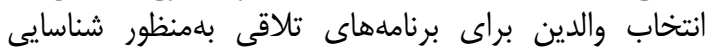

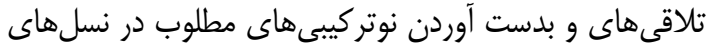

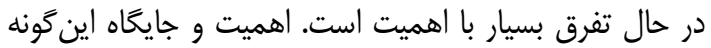

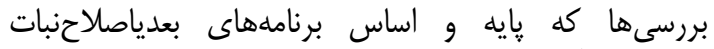

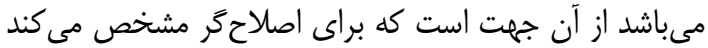

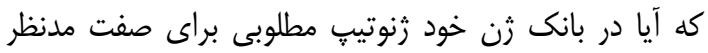

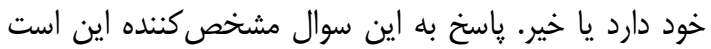


1. Arriel, N.H.C., A.O.D. Mauro, E.F. Arriel, S.H.U. Trevisoli, M.M. Costa, I.M. Barbaro and F.R.S. Muniz. 2007. Genetic divergence in sesame based on morphological and agronomic trait. Crop breeding and applied biotechnology, 7: 253-261.

2. Akbar, F., M.A. Rabbani, Z.K. Shinwari and S.J. Khan. 2011. Genetic divergence in sesame (Sesamumindicum L.) landraces based on qualitative and quantitative traits. Pakistan Journal of Botany, 43(6): 2737-2744 (In Persian).

3. Ashoka, V.R.P., S.M. Reddy, A.R.G. Ranganath and A. Dhanraj. 2001. Genetic variability and heritability for seed yield and its components in sesame (Sesamumindicum L.). Journal of oilseed research. Oil seed Res, 18: 173-175.

4. Bedigian D. and R. Harlan. 1986. Evdience for the cultivation of sesame in the ancient world. Economic Botany, 40: 137-154.

5. Bedigian, D., C. Smyth and J. Harlan. 1986. Patterns of morphological variation in sesame. Economic Botany, 40: 353-365.

6. Biabani, A.R. and H. Pakniyat. 2008. Evaluation of Seed Yield-Related Characters in Sesame (Sesamumindicum L.) Using Factor and Path Analysis. Pakistan Journal of Biological Sciences, 11: 1157-1160 (In Persian).

7. Bisht, I.S., R.K. Mahajan, T.R. Lokuathan and R.C. Agrawal. 1998. Diversity in Indian sesame collection and stratification of germplasm accessions in different diversity groups. Genetic Resources and Crop Evolution, 5: 325-335.

8. Falconer, D.S. and T.F.C. Mackey. 1996. Introduction to quantitative genetics. Longman Group Ltd. Harlow, UK, 187-246.

9. FAO. 2014. FAOSTAT. Food and agricultural commodities production. Available athttp: // faostat. fao. Org/ site/ 339/ default. aspx. FAO.

10. Furat, S. and B. Uzun. 2010. The use of agro-morphological characters for the assessment of genetic diversity in sesame (Sesamumindicum L.). Plant Omics Journal, 3: 85-91.

11. Geleta, M., T. Bryngelsson and E. Bekel. 2008. Assessment of genetic diversity of Guizotiaabyssinica (L.f.) Cass. (Asteraceae) from Ethiopia using amplified fragment length polymorphism. Plant Genetic Resources Characterization Utilization, 6: 41-51.

12. Khodarahmpour, Z. and M. Motamedi. 2016. Study of Genetic Diversity of Alfalfa (Medicago sativa L.) Genotypes Via Multivariate Analysis. Journal of Crop Breeding, 19: 163-169.

13. Krishnaiah, G., K.R. Reddy and M.R. Sekhar. 2002. Variability studies in sesame. Crop Research, 24 : 501-504.

14. Kumar, P.S., R. Sundararajan, P. Thangavel, P. Karuppiah and J. Ganeshan. 2002. Variability studies in the second generation of inter varietal crosses in Sesame (Sesamumindicum L.). Sesame and safflower Newsletter, 17: 36-39.

15. Mansouri, S., M.S. Najafabadi, M. Esmailov and M. Aghaee. 2014. Functional Factor Analysis In Sesame Under Water-Limiting Stress: New Concept On an Old Method. Plant Breeding and Seed Science, 70(1): 91-104 (In Persian).

16. Masoudi, B., M. Bihamta, H. Babaei and S. Peyghambari. 2008. Evaluation of Genetic Diversity for Agronomic, Morphological and Phenological Traits in Soybean. Seed and Plant Improvment Journal, 24(3): 413-427 (In Persian).

17. Mkamilo, G.S. and D. Bedigian. 2007. Sesamumindicum L. In H.A.M. van der Vossen and G.S. Mkamilo, eds. Vegetable Oils. Plant Resources of Tropical Africa [PROTA], 14: 153-158.

18. Navale, P.A., C.A. Nimbalkar and H.T. Gandhi. 2001. Genetic divergence in sesame. Journal of Maharashtra Agricultural Universities, 26: 144-146.

19. Salehi, M. and G. Saeidi. 2012. Genetic Variation of Some Agronomic Traits and Yield Component in Breeding Lines of Sesame. Jcb, 4(9): 77-92 (In Persian).

20. ShafieeKhorshidi, M., M.R. Bihamta, F. Khialparast and M.R. Naghavi. 2012. Assessment of Genetic Variation in Common Bean (Phaseolus vulgaris L.) Genotypes under Drought Condition Using Cluster and Canonical Discriminant Analysis (CDA). Journal of Crop Breeding, 10:1-17.

21. Sharma, B.D. and D.K. Hore. 1993. Multivariate analysis of divergence in upland rice. Journal of Agricultural Science, 63: 515-517.

22. Siva Prasad, Y.V.N., M.S.R. Krishna and V. Yadavalli. 2013. Correlation, path analysis and genetic variability for economical characteristics in F2 and F3 generations of the cross AVT $3 \times$ TC 25 in Sesame (Sesamum indicum L.). Journal of Environmental and Applied Bioresearch, 1(2): 14-18.

23. Sivaprasad, Y.V.N. and V. Yadavalli. 2012. Correlation, path analysis and genetic variability in F2 and F3 generations of cross Padma $\times$ JLSV 4 in sesame (Sesamumindicum L.). International Journal of Applied Agricultural Sciences, 2: 311-314.

24. Trehan, K.B., A.V. Rao, S.K. Mehta, H. Chand, H.N. Sharma and S.K. Baijal. 1974. Genetic divergence in sesame. InternationalJournal of Applied Agricultural Sciences, 44: 208-212.

25. Yol, E., E. Karaman, S. Furat and B. Uzun. 2010. Assessment of selection criteria in sesame by using correlation coefficients, path and factor analyses. Australian Journal of Crop Science, 4(8): 598. 


\title{
Evaluation of Genetic Diversity of Agronomic and Morphological Traits of Sesame Genotypes
}

\author{
Bahram Masoudi ${ }^{1}$ and Mehrzad Ahmadi ${ }^{2}$ \\ 1- Assistant Professor and expert, Seed and Plant Improvement Institute, Agricultural Research, Education and \\ Extension Organization (AREEO), Karaj, Iran, (Corresponding Author: bmasoudi@gmail.com) \\ 2- Expert, Seed and Plant Improvement Institute, Agricultural Research, Education and Extension Organization \\ (AREEO), Karaj, Iran \\ Received: June 20, 2018 \\ Accepted: June 26, 2019
}

\begin{abstract}
Success in a breeding program and selection programs depends on two factors of genetic diversity and effective selection of desirable genotypes. Therefore, studying the genetic diversity for traits and the use of this diversity is important for genetic improvement of the traits. In order to study the genetic diversity of yield and its components and some of the morphological and phonological traits, and to identify the important factors affecting yield, 91 new imported sesame genotypes with 3 checks ( Naztakshakhe, Oltan and Yellow-white) were studied in an augmented design and six blocks in Seed and Plant Improvement Research Institute, Karaj, Iran, in 2016. The studied genotypes showed good diversity for most of the traits, because the studied genotypes were from different geographic regions. Traits of number of capsules per branch, seed yield per plant, number of branches and total number of capsules per plant had the highest phenotypic variation coefficient. The results of factor analysis showed that six factors explained $82.7 \%$ of the data variation. These factors were named according to the traits that were included under the titles of performance characteristics and its components, capsule characteristics, phonological properties, seed quality characteristics, height factor and germination strength factor. The evaluated genotypes were classified into five groups based on cluster analysis for all evaluated traits. The results of cluster analysis showed that the grouping of genotypes were not related to geographical distribution of genotypes and most genotypes were grouped based on morphological differences. Canonical Discriminate Function via Fisher's linear method was able to confirm 95.7 percent of the validity of clustering analysis result. The four functions explained about $100 \%$ of variances among genotypes. In general, it can be concluded that new imported genotypes of sesame have a good variation for most traits and this variety can be used in breeding programs. In summary, Margo, Bukbak, Black chil sung, Q21115 (shattering selection) and Jungkyung genotypes have a good potential for increasing grain yield and can be used in future breeding programs.
\end{abstract}

Keywords: Cluster analysis, Discriminate function analysis, Diversity, Factor analysis, Sesame 